\title{
A Novel Study on Bipolar High Voltage Direct Current Transmission Lines Protection Schemes
}

\author{
Shobha Agarwal, C. K. Panigrahi, Aishwarya Sahoo, Sanitha Mishra \\ Department of Electrical Engineering, Kiit University, India
}

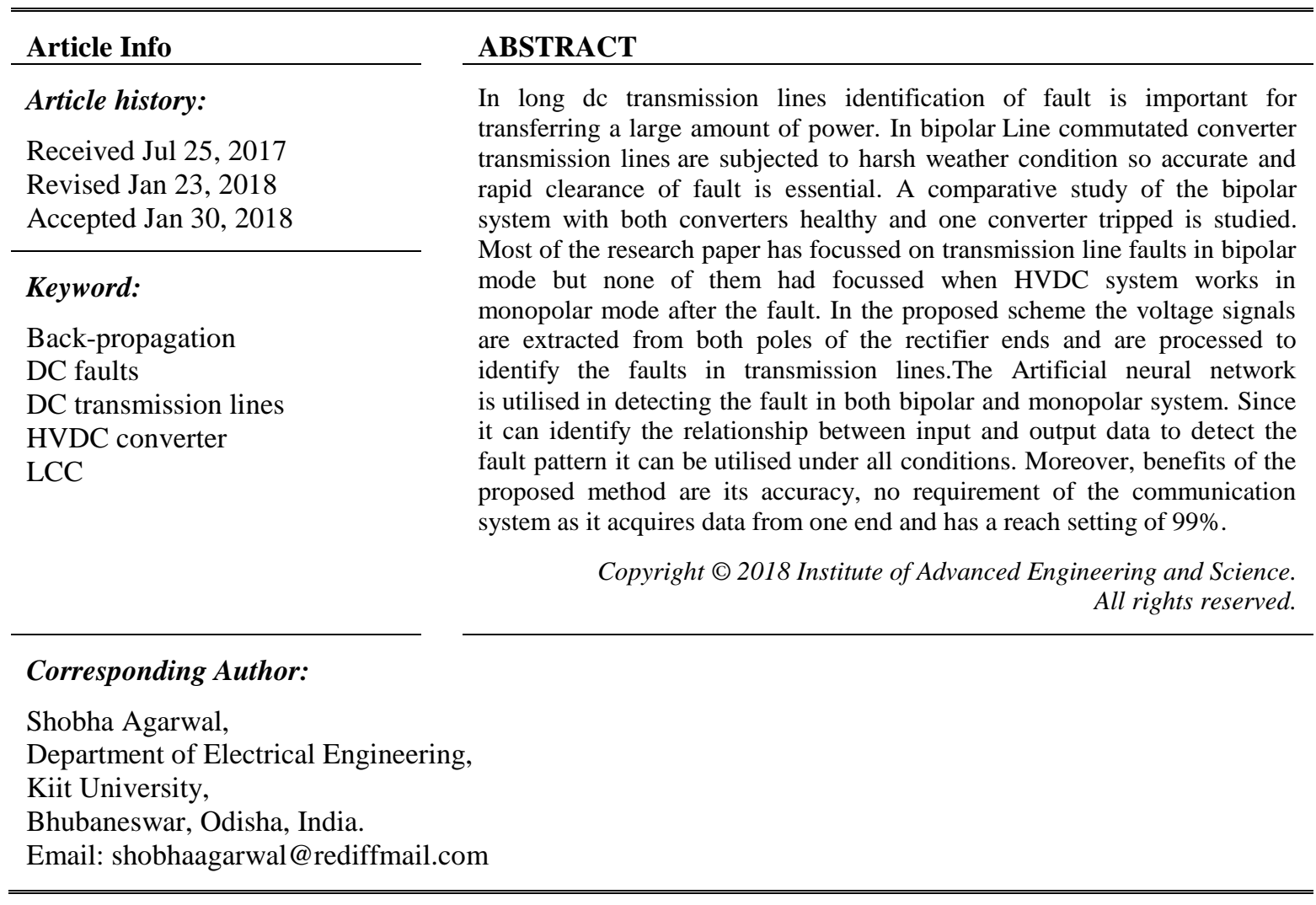

\section{INTRODUCTION}

HVDC transmission line finds widespread application in transmission of bulk power over long distance. The effect of ground impedance in the ac line has a disadvantage that under steady state it can affect the efficient power transfer but DC link has an advantage that ground impedance and its effect is negligible [1]. In [2], HVDC technology and reliability assessments on HVDC systems from a number of papers are reviewed. The paper is reviewed for increasing demand of power and penetration of HVDC system for quantitative assessment of dc link. The dc link can be used as an interconnection between two different frequencies. In [3], effect of discharging current on detection of fault is also considered. Some of the protection scheme is proposed in [4]-[8] but none of them had detected under half voltage operations. These schemes suffers from some of the disadvantages in sensitivity under high fault resistance, close up faults and requires data from both ends. VSC based multi terminals connection in wind farm subjected to dc faults are studied in [9]. In [10], wavelet based fault detection for fast detection of faults in VSC based HVDC is adopted. In [11]-[13] artificial neural network for fault identification is proposed but has not tested under half voltage opearation. Protection scheme is studied in detailed in distributed systems in [14]. In [15], soft computing using fuzzy, genetic algorithm, Back-propagation neural network (BPNN) based algorithm is proposed for pattern identification and maximum power point. In [16] distance protection is suggested for ac systems using Rogowski coil but it has been vaildated for low voltage and lacks in high voltage. In [17] NN based contoller is used for AC/DC systems and its performance are compared with conventional controller. Spectogram is used to identify and classify the harmonic signals in power system in distribution side but has 
not not discussed in transmission side [18]. In [19] wavelet based MRA is used for detecing the faults but has not been proved for time domain. The traveling wave has inherent problem in detecting the faults at high resistances in [20]. In [21] memory requirement will increase because computation is more and lacks the mathemetical model. High sampling frequency is a drawback and requirement of data from both ends are essential in [22]. This causes delay in time and synchronisation of data. The main contribution of the proposed work is that fault detection in Bipolar HVDC system with dc transmission line faults when one group of converter is tripped has been studied which none of the above paper has described. The paper is organised as follows - Section 2 describes the basic concept of ANN module using BPNN, Section 3 contains HVDC system topologies and the proposed method for fault detection, Section 4 contains the results, Section 5 contains the conclusion of the work.

\section{ARTIFICIAL NEURAL NETWORK ANALYSIS}

An artificial neural network (ANN) has artificial neurons and has a mathematical model or computational model. A neural network consists of an interconnected group of artificial neurons, and the information is processed as it comes from the neighboring neurons and leads an outcome of the process then neurons decide the output. The ANN system was developed using the MATLAB package for automatic selection. It has input structure for obtaining and processing the data for network training. For verification of trained network, its operations are checked with the results.

If $\mathrm{X}_{1}, \mathrm{X}_{2}, \mathrm{X}_{3}, \ldots \ldots \mathrm{X}_{\mathrm{n}}$ are the input neurons, $\mathrm{w}_{1}, \mathrm{w}_{2}, \ldots \ldots \ldots \mathrm{w}_{\mathrm{n}}$ are weighted interconnection links, $\left(\mathrm{x}_{1}, \mathrm{x}_{2}, \mathrm{x}_{3}, \ldots \ldots \ldots \mathrm{x}_{\mathrm{n}}\right)$ are the activation functions, $\mathrm{y}_{\text {in }}$ the output are represented using Equations (1)-(3)

$$
\begin{aligned}
& y_{i n}=x_{1} w_{1}+x_{2} w_{2}+x_{3} w_{3} \ldots \ldots \ldots \ldots \ldots \ldots x_{n} w_{n} \\
& y_{i n}=\sum_{i=1}^{n} x_{i} w_{i} \\
& y=\left(y_{i n}\right)
\end{aligned}
$$

\subsection{Pre-processing and feature extraction}

Pre-processing of voltage signal involves rms values of the instantaneous voltage signals. HVDC model is simulated using Matlab software and instantaneous voltage samples are obtained at relaying point.

\subsection{Training data set}

Preparation of training is done on the different location of fault for line to ground faults in bipolar HVDC. Fault Location

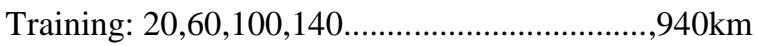

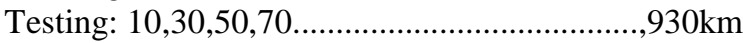

The total number of voltage samples used for training the neural network is half cycle data from the instant of fault.

\section{HVDC TOPOLOGIES}

\subsection{Asymmetrical monopole}

HVDC converter system has mainly two types of topologies Monopolar and Bipolar. The Monopolar HVDC is widely used with earth as ground return.

\subsection{Bipolar system}

In bipolar system both the poles carry current and is used to transfer large power. It has advantge that fault in one transmission line also causes current to flow through other transmission lines at reduced power. The two converters are connected from the AC source and has advantage that even if one converter is not operating or tripped the other converter carries half the power as shown in Figure 1. 


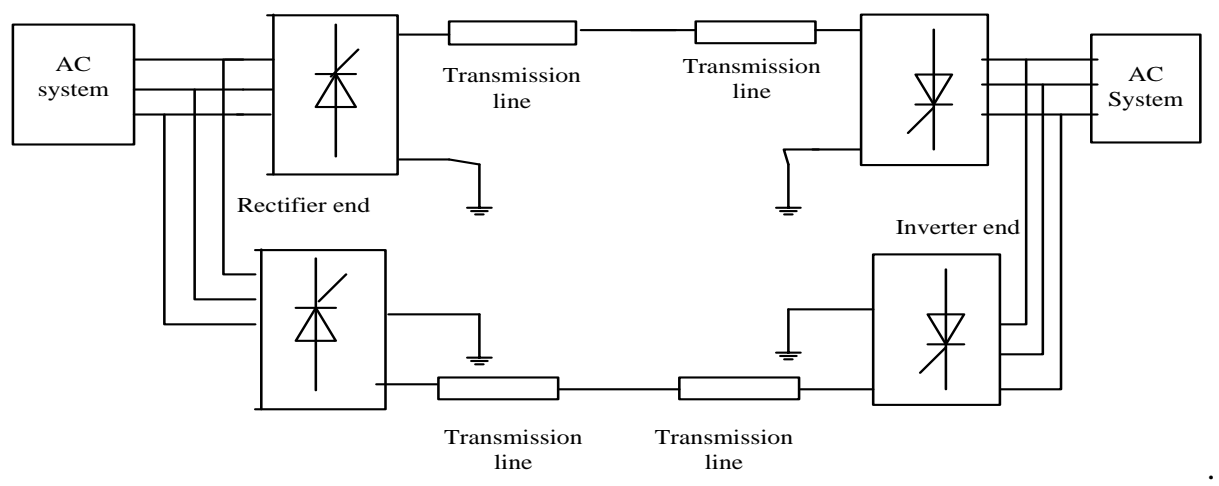

Figure 1. Bipolar system

\subsection{Twelve pulse converter}

In HVDC transmission 12 pulse converter is preferred and is made by connecting series combination of two bridges. One transformer $\mathrm{Y} / \mathrm{Y}$ for one bridge and other transformer $\mathrm{Y} / \Delta$ for another bridge is used for $30^{\circ}$ phase displacement. The dc link voltage is obtained from the two bridges and is the sum of individual dc voltages [1]. The equations represents various parameters in which $\mathrm{e}_{\mathrm{as}}, \mathrm{e}_{\mathrm{bs}}, \mathrm{e}_{\mathrm{cs}}$ are the secondary phase voltages from star-star transformer given to bridge $1, E_{L L}$ is line to line voltage, $e_{b c S}, e_{a c D}$ is line to line voltage in star connected winding and line to line voltage in delta connected winding, $v_{d}$ voltage for one interval, $V_{d c}$ is average dc voltage.

$$
\begin{aligned}
& e_{a S}=\sqrt{\frac{2}{3}} E_{L L} \sin \left(w t+150^{\circ}\right) \\
& e_{b S}=\sqrt{\frac{2}{3}} E_{L L} \sin \left(w t+30^{\circ}\right) \\
& e_{c S}=\sqrt{\frac{2}{3}} E_{L L} \sin \left(w t-90^{\circ}\right) \\
& e_{b c S}=\sqrt{2} E_{L L} \sin \left(w t+60^{0}\right) \\
& e_{a c D}=-\sqrt{2} E_{L L} \sin \left(w t-270^{0}\right) \\
& v_{d}=e_{b c S}+e_{a c D}=\sqrt{2} E_{L L} \sin \left(w t+60^{\circ}\right)-\sqrt{2} E_{L L} \sin \left(w t-270^{\circ}\right) \\
& V_{d c}=2 V_{d o} \cos \alpha=\frac{6}{\pi} \sqrt{2} E_{L L} \cos \alpha
\end{aligned}
$$

\subsection{Proposed fault detection method}

The proposed method is tested with a power system network designed in MATLAB/SIMULINK for $980 \mathrm{~km}$ transmission line. Bipolar system is built from monopolar in simulink from 12 pulse thyristorised based converter with power capacity of $1000 \mathrm{MW}(500 \mathrm{kV}, 2 \mathrm{kA})$. DC interconnection is used to transmit power from a $500 \mathrm{kV}, 5000 \mathrm{MVA}, 60 \mathrm{~Hz}$ system to a $345 \mathrm{kV}, 10000 \mathrm{MVA}, 50 \mathrm{~Hz}$. The following steps are done for the detection of a fault and are shown in the Figure 2.

a. The rectifier end signals with both converters working or pole to pole voltage are taken as an input.

b. The trained data is tested using algorithm backwards propagation neural network after normalising the data.

c. The training network has 30 neurons in hidden layer, tan-sig transfer function with lavenberg marquerdt algorithm as training algorithm.

d. The output layer detects the output.

e. This is tested for transmission line with fault in one converters of bipolar systems and if detects fault then output is HIGH. 


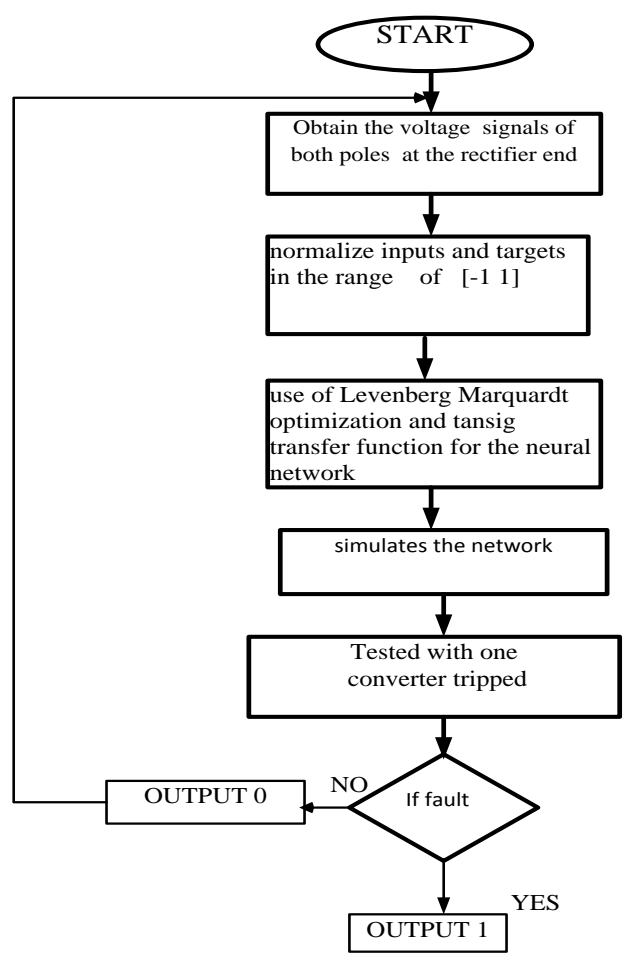

Figure 2. Flow chart for the proposed scheme

\section{RESULTS AND DISCUSSIONS}

The system under varying parameters are tested and tables are formed. In Table 1 varying fault location and detections results are shown. Bipolar system with both converters and one converter tripped for line to ground fault is verified. In Table 2 and Table 3 near end and far end fault location are tested for verification of results. Table 4 is formed for varying fault resistance because traveling wave protection finds difficult to detect faults for resistance more than $20 \mathrm{ohm}$. The detection time is calculated and is found to be less than a cycle.

\subsection{Performance of the method varying fault location during P1G fault in bipolar sytem and with one converter tripped}

For varying fault location $10,250,490,730,970 \mathrm{~km}$ with both converter working (bipolar system) and with one converter tripped (monopolar system) transmission line faults are analysed. The output signal becomes high and is shown by Table 1 .

Table 1. Performance of the Method Varying Fault Location during P1G Dault

\begin{tabular}{crc}
\hline Fault Location $(\mathrm{km})$ & $\begin{array}{c}\text { BPNN-D Bipolar with full voltage } \\
\text { operation } \\
\text { Output }\end{array}$ & $\begin{array}{c}\text { BPNN-D Bipolar with one 12 pulse } \\
\text { converter tripped } \\
\text { Output }\end{array}$ \\
\hline 10 & 1 & 1 \\
250 & 1 & 1 \\
490 & 1 & 1 \\
730 & 1 & 1 \\
970 & 1 & 1 \\
\hline
\end{tabular}

The results are analysed for P1G fault at $250 \mathrm{~km}$ as shown in the Figure 3 . Here fault occurs at $40 \mathrm{~ms}$ and is detected in $3 \mathrm{~ms}$ as shown in Figure 3(c) with both converters working. One of the converter is tripped and fault detection occurs at $4 \mathrm{~ms}$ as shown in the Figure 3(f). The controller identifies the pattern of fault and is detected within a cycle. In Figure 3(a) pole to pole voltage is shown and when fault occurs the pole voltage decreases. The pattern of fault is same in Figure 3(d) where pole voltage becomes half since monopolar operation occurs. In Figure 3(b) current in each pole is shown and when fault occurs it increases. The pattern of fault is same in Figure 3(e) where pole current increases. 

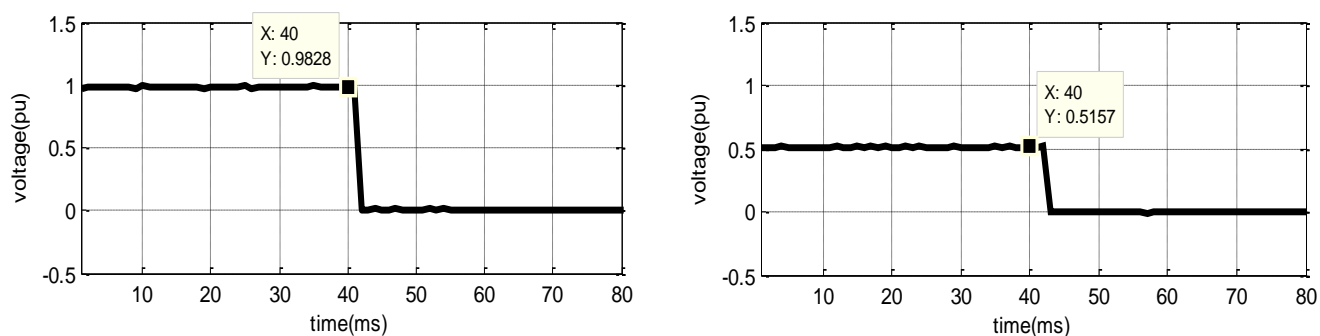

(a)
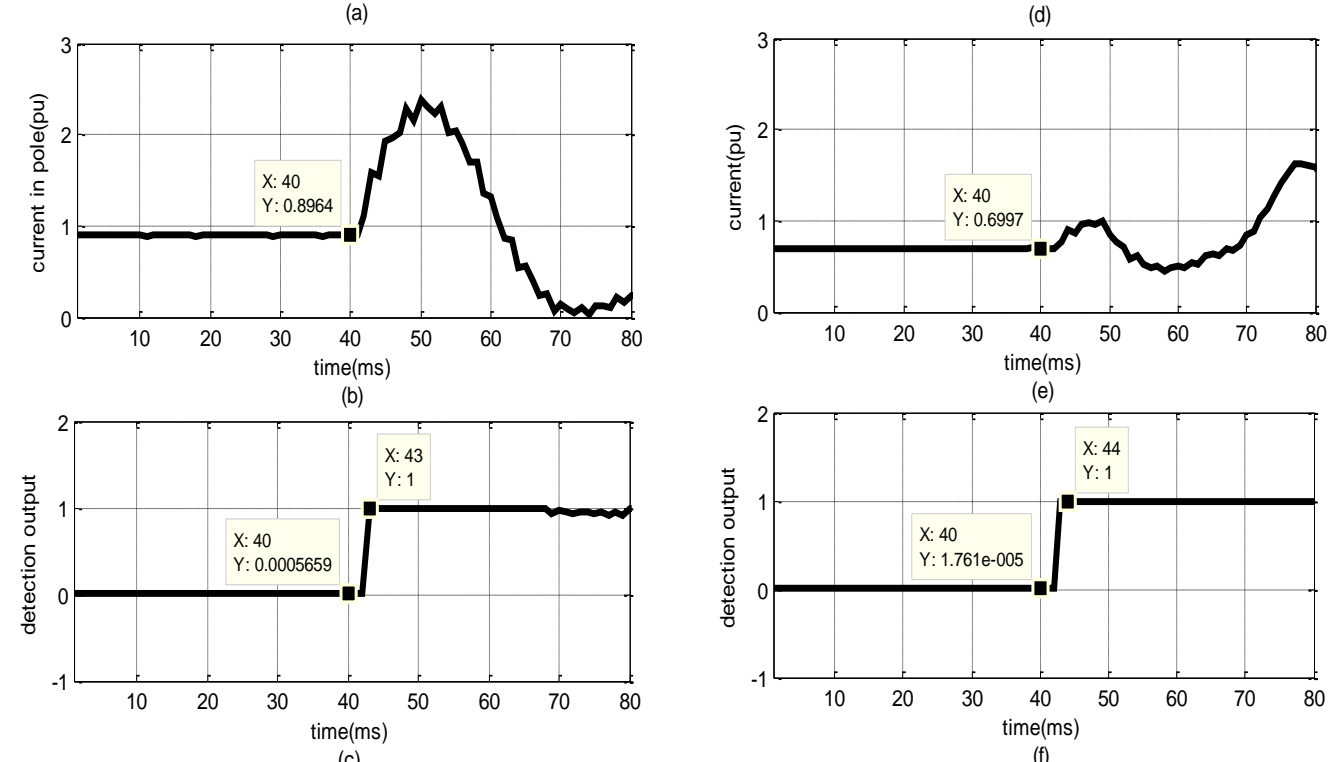

Figure 3. Signals during fault at distance of $250 \mathrm{~km}$ at $40 \mathrm{~ms}$ in bipolar system (a) Voltage between pole to pole (b) Current of each pole (c) Fault detection output (d) Voltage between pole to pole with one group of converter tripped (e) Current of each pole (f) Fault detection output.

\subsection{Performance of the method for near end p1g fault in bipolar sytem and with one converter} tripped

The results are analysed and shown in the Table 2 for P1G fault for near end locations. In the Table 2 detection output with time is shown for near end locations 1, 3.5, 6, 8.5km. In Figure 4 for location of $1 \mathrm{~km}$ fault occurs at $40 \mathrm{~ms}$ and is detected in $4 \mathrm{~ms}$ as shown in Figure 4(c) with both converters working. One of the converter is tripped and fault detection occurs at $3 \mathrm{~ms}$ as shown in the Figure 4(f).

Table 2. Performance of the Method in near end Faults

\begin{tabular}{|c|c|c|c|c|}
\hline \multirow[t]{2}{*}{ Fault Location $(\mathrm{km})$} & \multicolumn{2}{|c|}{ BPNN-D Bipolar with full voltage operation } & \multicolumn{2}{|c|}{$\begin{array}{c}\text { BPNN-D Bipolar with one } 12 \text { pulse converter } \\
\text { tripped }\end{array}$} \\
\hline & Time(ms) & output & Time(ms) & Output \\
\hline 1 & 4 & 1 & 3 & 1 \\
\hline 3.5 & 5 & 1 & 4 & 1 \\
\hline 6 & 7 & 1 & 5 & 1 \\
\hline 8.5 & 8 & 1 & 5 & 1 \\
\hline
\end{tabular}



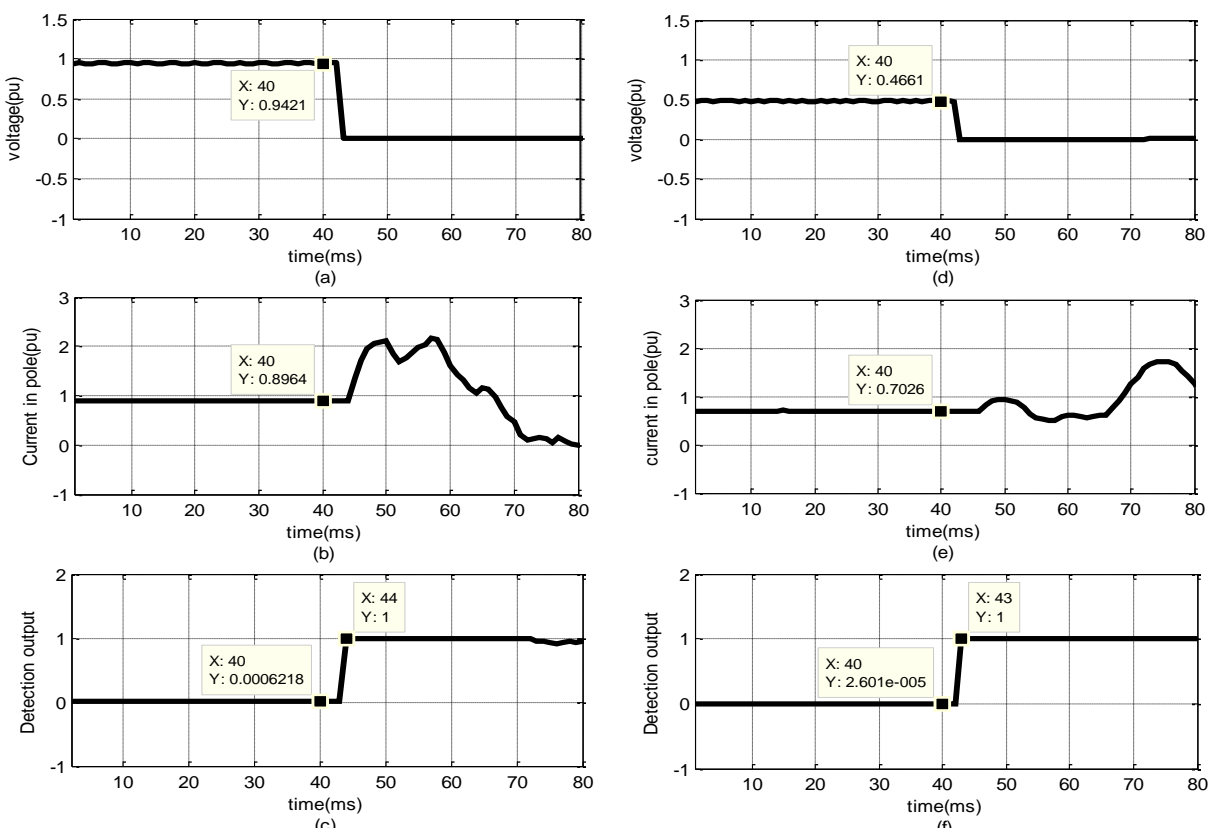

Figure 4. Signals during fault at distance of $971 \mathrm{~km}$ at $40 \mathrm{~ms}$ in bipolar system (a) Voltage between pole to pole (b) Current of each pole (c) Fault detection output (d) Voltage between pole to pole with one group of converter tripped (e) Current of each pole (f) Fault detection output

\subsection{Performance of the method for far end during p1g fault in bipolar sytem and with one converter tripped}

The far end results are analysed and shown in the Table 3 for varying locations at an interval of $2 \mathrm{~km}$ for P1G fault. The fault is varied from location of 971 and is tested upto $979 \mathrm{~km}$. The detection time increases with distance but is less than a cycle.

Table 3. Performance of the Method in Case of far end Faults

\begin{tabular}{llcll}
\hline Fault Location $(\mathrm{km})$ & \multicolumn{2}{c}{$\begin{array}{c}\text { BPNN-D Bipolar with full voltage } \\
\text { operation }\end{array}$} & \multicolumn{2}{c}{$\begin{array}{l}\text { BPNN-D Bipolar with one group of 12 } \\
\text { pulse converter tripped }\end{array}$} \\
& Output & Time $(\mathrm{ms})$ & Output & Time(ms) \\
\hline 971 & 1 & 4 & 1 & 3 \\
973 & 1 & 6 & 1 & 5 \\
975 & 1 & 8 & 1 & 7 \\
977 & 1 & 8 & 1 & 9 \\
979 & 1 & 11 & 1 & 9 \\
\hline
\end{tabular}

4.4. Performance of the method for varying resistance during P1G fault in bipolar sytem and with one converter tripped

The method is tested for varying resistances and are shown in the Table 4 for P1G fault. The resistances are varied from 0 to $100 \mathrm{ohm}$ and detection time is measured and the detection time is less than half of a cycle.

Table 4. Performance of the Method Varying Fault Resistance

\begin{tabular}{lllll}
\hline $\begin{array}{l}\text { Fault } \\
\text { Resistance } \\
(\Omega)\end{array}$ & \multicolumn{1}{c}{ BPNN-D Bipolar with full voltage operation } & \multicolumn{2}{c}{ BPNN-D Bipolar with one group of 12 pulse converter } \\
tripped & & Time $(\mathrm{ms})$ & Output \\
\hline 0 & Time $(\mathrm{ms})$ & output & 3 & 1 \\
20 & 3 & 1 & 4 & 1 \\
40 & 4 & 1 & 5 & 1 \\
60 & 6 & 1 & 6 & 1 \\
80 & 7 & 1 & 7 & 1 \\
100 & 8 & 1 & 7 & 1 \\
\hline
\end{tabular}




\section{CONCLUSION}

The proposed scheme ANN based fault detection method is implemented in bipolar transmission lines but is also suited for monopolar transmission lines with ground return. LCC based converters are trained from the ANN controller can identify the pattern of faults. There can be change in configuration of HVDC but controllers made from ANN remains the same. The advantages of the proposed fault scheme can be outlined as follows:

a. The proposed method is robust against variation of fault resistance and distance

b. It detects the faults within a cycle.

c. The accuracy, reliability, robustness is very high as high fault resistances faults can be determined.

d. Unlike travelling wave based methods it can detect near end and high fault resistance faults without any problem.

\section{REFERENCES}

[1] K.K. Padiyar, "HVDC power transmission systems", Second revised edition, New age international publisher.

[2] Johan Straus, Lina Bertling, "Introduction to HVDC Technology for Reliable Electrical Power Systems", Proceedings of the 10th International Conference on Probabilistic Methods Applied to Power Systems, 2008, PMAPS '08.

[3] X. Zheng, T. Nengling, Y. Guangliang, D. Haoyin, "A transient protection scheme for HVDC transmission line", IEEE Trans. Power Del. 2012, vol. 27, no. 2, pp. 718-724.

[4] H. Livani, C.Y. Evrenosoglu, "A single-ended fault location method for segmented HVDC transmission line", EPSR, 2017, vol. 107, pp. 190-198.

[5] J.Upendar, C. P. Gupta, G. K. Singh, “ANN Based Power System Fault Classification”, IEEE Region 10 Conference TENCON, 2008.

[6] Yi Wang, Ziguang Zhang, Yuan Fu, Yang Hei, Xiangyu Zhang, "Transmission Line of DC Grids Based on VSC", IEEE 8th International Power Electronics and Motion Control Conference (IPEMC-ECCE Asia), 2016.

[7] X.D. Zheng, N.-L. Tai, J.S. Thorp, G.-L. Yang, "A transient harmonic current protection scheme for HVDC transmission line", IEEE Trans. Power Delivery, 2012, vol. 24, pp. 2278-2285.

[8] Z. Xiaodong, N. Tai, G. Yang, H. Ding, "A transient protection scheme for HVDC transmission line" IEEE Trans. Power Delivery, 2012, vol. 27, pp. 718-724.

[9] Y. Zhang, N. Tai, and B. Xu, "Fault analysis and travelling-wave protection scheme for bipolar HVDC lines", IEEE Trans. Power Del., 2012, vol. 27, no. 3, pp. 1583-1591.

[10] Xiaodong, Z., Nengling, T., Thorp, J.S., et al., "Improved differential protection scheme for long distance UHVDC transmission line", Proc. Int.Conf. Power Energy Soc. Gen. Meeting, 2014 pp. 1-5.

[11] L. Xiaolei, A.H. Osman, O.P. Malik, "Hybrid traveling wave/boundary protectionfor monopolar HVDC line", IEEE Trans. Power Delivery, 2009, vol. 24, pp. 569-578.

[12] K. De Kerf, K. Srivastava, M. Reza, D. Bekaert, S. Cole, D. Van Hertem, and R. Belmans, "Wavelet-based protection strategy for DC faults in multi-terminal VSC HVDC systems", Inst. Eng. Technol.Trans. Gen., Transm. Distrib., 2011, vol. 5, no. 4, pp. 496-503.

[13] L.L. lai, F. Ndeh-che, "Fault Identification of HVDC System with Neural Network", Proceeding of 5th European conference on power Electronics and Application, 1994, pp. 31-263.

[14] Y. M. Yeap, and A. Ukil, "Wavelet Based Fault Analysis in HVDC System", in Proc. IECON 2014 - 40th Annual Conference on IEEE Industrial Electronics Society, Dallas, USA. 2014.

[15] Dr.S.N Sivanandam, Dr.S.N Deepa, Principle of soft computing, Wiley, 2nd edition.

[16] A. N. Sarwade1, P. K. Katti, J. G. Ghodekar, "Reach and Operating Time Correction of Digital Distance Relay,"International Journal of Electrical and Computer Engineering (IJECE), vol. 7, no. 1, pp. 58-67, February 2017.

[17] B.Nagu, P.V. Ramana Rao, M. Sydulu, "Enhancement of AC System Stability using Artificial Neural Network Based HVDC Controls," International Journal of Electrical and Computer Engineering (IJECE), vol. 3, no. 4, pp. 441-455, August 2013.

[18] M. H Jopri, A. R Abdullah, M. Manap, M. R Yusoff4, T. Sutikno, M. F Habban, "An Improved Detection and Classification Technique of Harmonic Signals in Power Distribution by Utilizing Spectrogram", International Journal of Electrical and Computer Engineering (IJECE), 2017, vol. 7, no. 1, pp. 12-20.

[19] K. Satyanarayana, Saheb Hussain MD, B.Ramesh, "Identification of Faults in HVDC System using Wavelet Analysis," International Journal of Electrical and Computer Engineering (IJECE), 2012, vol. 2, no. 2, pp. 175-182.

[20] Y. Zhang, N. L. Tai, and B. Xu, "Fault analysis and travelling-wave protection scheme for bipolar HVDC lines", IEEE Trans. Power Del., 2012, vol. 27, no. 3, pp. 1583-1591.

[21] Jiyang Wu, Haifeng Li, Gang Wang, and Yuansheng Liang, "An Improved Travelling-Wave Protection Scheme for LCC-HVDC Transmission Lines”, IEEE Transactions on Power Delivery, 2017, vol. 32, no. 1, pp. 106-116.

[22] Shu-ping Gao, Qi Liu, Guo-bing Song, "Current differential protection principle of HVDC transmission system", IET Gener. Transm. Distrib., 2017, vol. 11, no. 5, pp. 1286-1292. 


\section{BIOGRAPHIES OF AUTHORS}

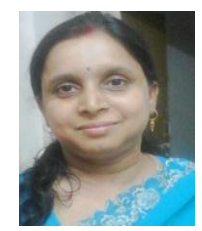

Shobha Agarwal did her B.Tech from NIT Patna and M.Tech from IIT Delhi. She is presently working as Assistant professor in KIIT university and is pursuing Phd degree from the KIIT University.

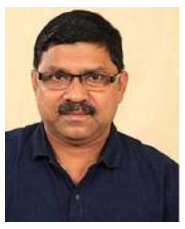

Chinmoy Kumar Panigrahi completed his B.Tech and M.Tech from Sambalpur University. $\mathrm{He}$ did his $\mathrm{PhD}$ from Jadavpur University in power system Engineering. He is presently working as Dean school of Electrical Engineering in Kiit university.

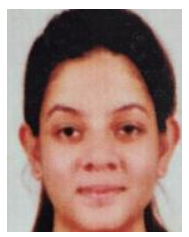

Aishwarya Sahoo has completed her B.Tech from I.T.E.R in 2016 and presently pursuing M.Tech degree from KIIT University.

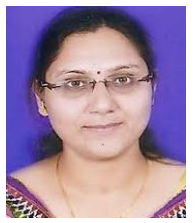

Sanitha Mishra did her B.Tech from OSME Keonjhar and M.Tech from Sambalpur University. She is presently working as Assistant professor in KIIT university and is pursuing Phd degree. 